\title{
Highlights of Mycology from Nineteenth Century to the International Space Station
}

\author{
Bassols AC* \\ Hospital Angeles del Carmen, Mexico
}

*Corresponding author: Angel Carlos Bassols, Hospital Angeles del Carmen, Guadalajara, Mexico,Email: acbassols@gmail.com

\section{Mini Review}

Volume 3 Issue 1

Received Date: January 02, 2020

Published Date: January 17, 2020

DOI: $10.23880 /$ oajmms-16000114

"Single-called fungi, the large taxonomic group to which Histoplasma capsulatum belongs may have appeared in the primordial sea about one billion years ago."

Gerard Baum

The story of Histoplasmosis*

Abbreviations: IMA: International Mycological Association; IFI: Invasive Fungal Infections; MPA: Multiplex Probe Amplifcation; ISS: International Space Station

\section{Mini Review}

For young physicians used to having electricity and born in the internet era it is hard to imagine how research was done in the Early Nineteen Century. Bright people like Christiaan Hendrik Persoon stand out because of his large contributions to Mycology. He published several books; one of the most important is Synopsis Methodica Fungorum, written in Latin. This book is considered the "foundation of systemic mycology". This book is the first one to adopt the Linnean method in mycology $[1,2]$.

The Nineteen Century is considered the transition of amateur Natural History to a professional practice, a field considered mostly for men. Johanna Westerdijk was the first Professor of Mycology in the Netherlands. She is considered one of the first women to challenge stereotypes because the inequality gap was even wider than it is now. We will mention some of the names of the pioneer scientist working on fungi taxonomy: Catharina Helena Dörrien, Marie-Annie Libert, Mary Elizabeth Banning, Elise-Caroline Bommer nee Destree, Mariette Rousseau and Annie Lorrain Smith. All of these women showed they could carry out outstanding research. In addition, they showed women were as capable of publishing important research as anyone [3].

Recent analyses suggest fungi (including yeast and mold) are the second most diverse kingdom on Earth with 99,000 known species. In fact, there are estimates of more than several million species of which around 600 may infect to humans $[4,5]$.

The discovery of Penicillium by Fleming in 1928 and subsequent research by Ernest Boris Chain and Edward Walter Florey in 1940 undoubtedly has been a milestone in Biology and Medicine. This mold properties and medical applications had dramatically altered the medical practice as well as life expectancy of the human kind $[6,7]$.

Earlier than 1960s the study of fungi was a branch of Botany. Some of the most important texts that study mycology are: "Pathological Mycology" by German S Woodhead and Arthur Hare, et al. [8], "Dictionary of the fungi" by Geoffrey Ainsworth, et al. [9]. Since its appearance in 1945, it constitutes an essential handbook for the detailed study of fungi. In later editions, more names have been added to the list, reaching 20,000 thus achieving the best list of generic names and were completed with the most recent molecular evidence that exists in this area of studies.

"Medical mycology in the USA historical analysis" by Ana Victoria Espinel Ingroff, et al. [10], that book reminds us, Agostino Bassi, was the first to associate silkworm disease with a fungus in 1835 .

This text is essential to understand the evolution of Medical Mycology in the US and Europe in the past 150 years. It highlights the importance of scientists who have had a high 


\section{Open Access Journal of Mycology \& Mycological Sciences}

impact on the progress of science, improving the knowledge necessary for the development of new antifungal drugs.

Aya Homei, et al. [11] "Fungal disease in Britain" and the United States 1850-2000. In this book, four diseases of high social impact in the period 1850-2000 are described in depth:

$>$ Dermatophytosis,

$>$ Infection with Candida Albicans,

$>$ Coccidoidomycosis, Blastomycosis and Histoplasmosis as specific infection in North America and finally

$>$ Infection with Aspergillus fumigatus.

Meanwhile, in Latin America San Blas, et al. [12] refers to the advances in mycology during the late Nineteen Century as the transition from magic to science. He mentions academics such as Alejandro Posadas, R. Seeber, A. Lutz and P. Almeida as founders of regional knowledge because they discovered agents of fungal disease.

It is important to understand the historical context of research in particular in Mycology. A fine example is the document written by Flores, et al. [13]. They describe how to confirm the infection Sporotrichum schenckii only forty years ago. First, they took a sample of the purulent material taken from the wound. Afterwards, the sample was inoculated in Sabouraud-glucose agar and then grown at $37^{\circ} \mathrm{C}$. Subsequently, the fungal culture was examined with a light microscope. In addition, there was an analysis of sugar fermentation and afterwards the samples were inoculated for in vivo testing [14].

One of the greatest academic efforts of modern study of mycoses is the establishment of The International Mycological Association IMA [15]. They have organized nine international congresses, involving more than forty countries, managing to establish Mycological organizations throughout the world $[16,17]$.

Why is it vital to have an early diagnosis for deep fungal infections?

An increase in the incidence of endemic and opportunistic fungal systemic diseases was discovered by Sifuentes Osornio, et al. [18]. This trend has population related drivers such as migration, tourism and population growth. Another cause of the upsurge of mycosis are the cases of Invasive Fungal Infections (IFI) associated with the management of HIV-positive patients, hematopoietic stem cell transplantation, aggressive chemotherapy for cancer, and autoimmune diseases with biological drugs. These therapies are more frequent and successful in recent years. Several Latin American studies showed that up to $4 \%$ of sepsis cases associated with catheters are related to Candida sp. resulting in high mortality rates that varies between $20-63 \%$ [19-22].
Candida auris is considered an emerging multi-drug resistant pathogen. In fact, $C$. auris alone has been reported in hospital outbreaks of more than 20 countries since 2009, it is resistant to the three main classes of antifungals. What makes it even more dangerous is the fact cases often go unnoticed because of laboratory misdiagnoses. Invasive candidiasis is one of the most common nosocomial fungal infections worldwide [23-24].

The raise in mycotic infections has made adequate fungi detection vital for the survival of patients. For instance, conventional microbiological techniques (blood cultures) are only positive in $38-50 \%$ of proven cases of invasive candidiasis, in addition the cell wall markers have low specificity and sensibility making immunological detection of fungi difficult. Fungal nucleic acid detection search appears to be suitable for the early identification of fungal pathogens. A molecular methodology based on real-time PCR has given a more accurate detection, example of this type of diagnosis are: Genesig kit (Primer Design), qPCR kit Vi Prime PLUS Candida albicans (Vivantis) or the Luminex XTAG fungus assay (Luminex Molecular Diagnostics).

Recently Jainlabdin MH, et al. [25] developed alternative method of diagnostic tools, known as Multiplex Probe Amplifcation (MPA) it can identify up to nine species of Candida (C. albicans, C. dubliniensis, C. tropicalis, C. parapsilosis, C. guilliermondii, C. haemulonii, C. krusei, C. glabrata and C. auris).

\section{Inside Human Body and Space Exploration}

Fungi are ubiquitous organisms that have accompanied humans over the centuries and will continue to do so. This group will continue to be important for humanity which means further research is and will be needed.

The film "Bohemian Rhapsody Queen's story" sparked the interest in further knowledge of Pneumocystis jirovecii. This microorganism was originally wrongly described by Chagas in 1909 as part of the biological cycle of a protozoan. Nevertheless it was reclassified as a fungus in 1988 [26].

Mogilnicka and Ufnal research suggest microbiota plays a crucial role in the homeostasis of the human host. These microorganisms are not exclusively bacteria; human intestine also shelters several species of fungi which produce numerous metabolites. A wide variety of the food and beverages we ingest contain a broad spectrum of fungi which have their own metabolites. This could become the molecular markers of the future [27].

Technology has made it easier of humanity to explore space. Space travel, however, depends on working and living 


\section{Open Access Journal of Mycology \& Mycological Sciences}

in a confined environment, making necessary to reuse air and water for months. If this process is not made properly space travelers would end up living in dangerous conditions for long-term health. Using space wisely is vital, because the crew has limited contact with the rest of the world, in a very demanding workplace where stress levels are very high. There have been experiments looking for the relationship between stress and microbial contamination, under those conditions [28].

Salmonella typhimurium grown under microgravity conditions has shown an increased level of tumor necrosis factor alpha in infected epithelial cells. This usually means an increase in microorganism's virulence. Astronauts face high levels of radiation, microgravity, persistent fluid dynamics, prolonged isolation, confinement, chronical detachment of the circadian cycles in addition of extensive working hours. The immune system has serious alterations due to the increased burden of chronical stress. A six-month space flight, can eventually lead to persistent reactivation of latent herpes viruses and the possibility of developing a malignant disease [28-32].

However experts like Peter W Taylor, et al. [33] reports that the International Space Station (ISS) has been habitable for more than 15 years. The key components of guarantying human survival are accurate prediction of microbiological problems in order to avoid problems that complicate future deep space exploration. Although highly efficient air filtration systems, microbiological monitoring are used and the aim is to minimize the accumulation of moisture inside, routine cleaning of the interior surfaces continues as a great challenge [34].

One of the objectives of this report would be to stimulate scientific production in areas of infectious diseases and Mycology a particular emphasis on the current knowledge of their cellular and molecular biology; and another is not to forget the work of those who developed modern mycology. Since it is surprising the growing popular interest for the knowledge of fungi, it was due to the scourge of Victorian classrooms (Trichophytum, Microsporum and Epidermophytum) and the proliferation of the so-called "athlete's foot" in the years after World War II (Trichophyton rubrum and Trichophyton metagrophytes). Now, in the past thirty years, the appearance of opportunistic fungal infections, associated with medical progress in the world (Critical Medicine and invasive medical interventions, drugs produced severe immunosuppression) are again in the public domain $[35,36]$.

Scientific expeditions beyond Earth orbit present huge challenges in order to preserve the health of those on board. So while culture of the most prominent fungal human pathogen (Candida albicans) in microgravity, potentiates a global change in gene expression that could induce a virulence-related phenotype, in the study of Crabbe, at al. [37]. Data represent an important basis for the assessment of the risk that commensal flora could play during prolonged human spaceflight missions [38].

\section{References}

1. Mushroom: Magazine highlight: Hunting Boletes in Sardinia. The Journal of Wild Mushrooming.

2. Chater AO, Brummitt RK (1966) Subspecies in the Works of Christiaan Hendrik Persoon. Taxon 15(4): 143-149.

3. Maroske S, May TW (2018) Naming names: the first women taxonomists in mycology. Stud Mycol 89: 63-84.

4. Satyanarayana T, Deshmukh SK, Deshpande M Advancing Frontiers in Mycology \& Mycotechnology, Basic and Applied Aspects of Fungi. Chapter 3, Springer pp: 675.

5. Pal M (2019) Contribution of Prof. Dr. Mahendra Pal in Veterinary and Medical Mycology. J Mycol Mycological Sci 2(2): 1-2.

6. Garcia Hernandez M (2011) From classical to modern mycology. Medicina Universitaria 13(53): 225-226.

7. Becerra Jimenez JM (2013) Aplicación of the scientific method in the discovery of penicillin. Science Autonomous University of Coahuila.

8. Woodhead GS, Hare AW (1885) Pathological mycology; an enquiry into the etiology of infective diseases. In: Edinburgh, Pentland YJ, et al. (Eds.), pp: 174.

9. Ainsworth G (1943) Ainsworth \& Bisby's dictionary of the fungi. In: Hawksworth DL, Sutton BC, Ainsworth, Ainsworth GC, et al. $7^{\text {th }}$ (Edn.), Wallingford, Oxon, UK.

10. Espinell Ingroff AVE (2003) Medical Mycology in the United States: a historical analysis (1894-1996). Kluwer Academic Publishers, pp: 221.

11. Homei A, Worboys M (2013) Fungal disease in Britain and the United States 1850-2000: Mycoses and Modernity. Science, Technology and Medicine in modern history 30(4): 840-842.

12. San Blas G (2000) From magic to science: a journey throughout Latin American medical mycology. Med Mycol 38 (S1): 1-8.

13. Flores C, Perrada L, De la Parra M (1982) Mycological and experimental study in a case of Sporotricosis. Mycology Bulletin 1(1): 39-42. 


\section{Open Access Journal of Mycology \& Mycological Sciences}

14. De Barros MBL, De Paes AR, Schubach OA (2011) Sporothrix schenckii and Sporotrichosis. Clinical Microbiology Review 24(4): 633-654.

15. Simmons EG (2010) The International Mycological Association: its history in brief with summaries of its International Mycological Congresses and diverse international relationships. IMA Fungus 1(1): 18-100.

16. Hawksworth DL (2003) Monitoring and safeguarding fungal resources worldwide: the need for an international collaborative MycoAction Plan. International Mycological Association 13: 29-45.

17. Slavin MA, Chakrabarti A (2012) Opportunistic fungal infections in the Asia-Pacific region. Med Mycol 50(1): 18-25.

18. Sifuentes Osornio J, Corzo Leon DE, De Leon APL (2012) Epidemiology of Invasive Fungal Infections in Latin America. Curr Fungal Infect Rep 6(1): 23-34.

19. Colombo AL, Guimaraes T, Silva LR, De Almeida Monfardini LP, Cunha AK, et al. (2007) Prospective observational study of candidemia in Sao Paulo, Brazil: incidence rate, epidemiology and predictors of mortality. Infect Control Hosp Epidemiol 28(5): 570-576.

20. Diaz Granados CA, Martinez A, Deaza C, Valderrama S (2008) An outbreak of Candida spp. bloodstream infection in a tertiary care center in Bogota, Colombia. Braz J Infect Dis 12(5): 390-394.

21. Hernandez Duenas AMR, Vazquez Larios MR, Soto Nieto GI, Rivera Martinez E (2009) Drug susceptibility of yeasts isolated from books from patients of the Instituto Nacional de Cardiologia Ignacio Chavez. Rev Inv Clin 61: 294-299.

22. Hart E, Nguyen $M$, Allen M, Clark CM, Jacobs DM (2019) A systematic review of the impact of antifungal stewardship interventions in the United States. Ann Clin Microbiol Antimicrob 18(1): 24.

23. Forsberg K, Woodworth K, Walters M, Berkow EL, Jackson B, et al. (2019) Candida auris: The recent emergence of a multidrug-resistant fungal pathogen. Med Mycol 57(1): 1-12.

24. Sears D, Schwartz BS (2017) Candida auris: An emerging multidrug-resistant pathogen. Int J Infect Dis 63: 95-98.

25. Jainlabdin $\mathrm{MH}$, Batra A, Paredes SE, Hernandez FH, Fu G, et al. (2019) Single-tube, dual channel pentaplexing for the identification of Candida strains associated with human infection. Scientific Reports 9: 14692.
26. Aguilar VJM, Ortega MFJ, Sandubete CE (2006) Pneumocystis jiroveci: a new name for an old pathogen. Rev Clin Esp 206(6): 278-280.

27. Mogilnicka I, Ufnal M (2019) Gut Mycobiota and Fungal Metabolites in Human Homeostasis. Curr Drug Targets 20(2): 232-240.

28. Norbiato G, Vago T, Battocchio L (1998) Microbial and fungal contamination contributes to physical stress in space flight: studies in the Euromir-95 mission. J Gravit Physiol 5(1): 145-146.

29. Wong WC, Oubre C, Mehta SK, Ott MC, Pierson DL (2017) Preventing Infectious Diseases in Spacecraft and Space Habitats. In: Hurst CJ, et al. (Eds.), Modeling the Transmission and Prevention of Infectious Disease. Springer 4: 3-17.

30. Crucian BE, Chouker A, Simpson RJ, Mehta S, Marshall G (2018) Immune System Dysregulation During Spaceflight: Potential Countermeasures for Deep Space exploration Missions. Front Immunol 9: 1437.

31. Chopra V, Fadl AA, Sha J, Chopra S, Galindo CL, et al. (2006) Alterations in the virulence potential of enteric pathogens and bacterial-host cell interactions under simulated microgravity conditions. J Toxicol Environ Health A 69(14): 1345-1370.

32. Sonnenfeld G, Shearer WT (2002) Immune function during space flight. Nutrition 18(10): 899-903.

33. Taylor PW (2015) Impact of space flight on bacterial virulence and antibiotic susceptibility. Infection and Drug Resistance 8: 249-262.

34. Esper RC, Diaz Ponce JA, San Juan LP (2016) Mesa Directiva de la Academia Nacional de Medicina de México. Medicina Espacial, pp: 402.

35. Arenas Guzman R (2004) Superficial Mycoses. Gac Med Mex 140(2): 185.

36. Rubio MC, Rezusta A, Gil Tomas J, Ruesca RB (1999) Perspectiva micológica de los dermatofitos en el ser humano. Rev Iberoam Micol 16: 16-22.

37. Crabbe A, Nielsen Preiss SM, Woolley CM, Barrila J, Buchanan K, et al. (2013) Spaceflight Enhances Cell Aggregation and Random Budding in Candida albicans. PLoS ONE 8(12): e80677.

38. Daniel TM, Baum GL (2004) Drama and Discovery: The story of Histoplasmosis. Bulletin of the History of Medicine 78(2): 503-504. 